
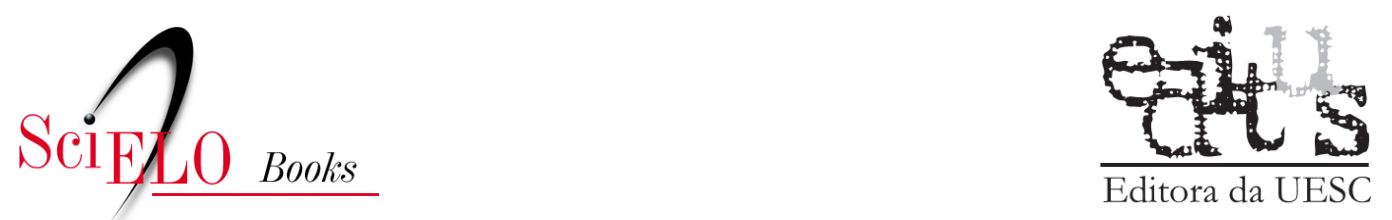

\title{
Representação social da pessoa idosa percepções de jovens-adultos do estado de Goiás
}

\author{
Ivone Félix de Sousa \\ Marli Bueno de Castro \\ Wanny Carolie Teixeira Nunes \\ Larissa Cole
}

\section{SciELO Books / SciELO Livros / SciELO Libros}

SOUSA, I. F., CASTRO, M. B., NUNES, W. C. T., and COLE, L. Representação social da pessoa idosa: percepções de jovens-adultos do estado de Goiás. In: D'ALENCAR, R. S., ed. A representação social na construção da velhice [online]. Ilhéus, BA: EDITUS. 2017, pp. 115-133. ISBN: 978-85-7455-486-0. https://doi.org/10.7476/9788574554860.0006.

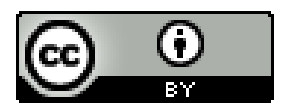

All the contents of this work, except where otherwise noted, is licensed under a Creative Commons Attribution 4.0 International license.

Todo o conteúdo deste trabalho, exceto quando houver ressalva, é publicado sob a licença Creative Commons Atribição 4.0.

Todo el contenido de esta obra, excepto donde se indique lo contrario, está bajo licencia de la licencia Creative Commons Reconocimento 4.0. 


\title{
REPRESENTAÇÃO SOCIAL DA PESSOA IDOSA: PERCEPÇÕES DE JOVENS-ADULTOS DO ESTADO DE GOIÁS
}

\author{
Ivone Félix de Sousa \\ Marli Bueno de Castro \\ Wanny Carolie Teixeira Nunes \\ Larissa Cole
}

\section{Introdução}

Nas últimas décadas, embora as discussões acadêmicas tenham fomentado a percepção sobre o aumento do número de idosos na sociedade brasileira, as pesquisas no Brasil têm registrado pouca participação significativa da população em pesquisas referentes à temática da velhice e do envelhecimento (SOUSA; CASTRO; SÁ, 2012). Nesse sentido, o crescimento populacional relativo à pessoa idosa, tanto em termos absolutos, quanto proporcionais (TERRA; SILVA; SCHIMIDT, 2009) é um fenômeno que deve ser estudado em diferentes dimensões, para melhor compreendê-lo.

De acordo com dados do IBGE (2010), a população com idade acima de 60 anos, no Brasil, é de 10,8\% e espera-se que esta, em 2025, chegue a 1,2 bilhões. Em Goiás, a porcentagem de pessoas idosas em relação à população total é de 9,4\% e em Goiânia é de 9,6\%. Em Goiânia, especificamente, existem 2.330 idosos com idade acima de 90 anos. 
Existem diferentes estudos que abordam esta temática 'pessoa idosa'. São estudos desenvolvidos para entender a qualidade de vida, a saúde física e psíquica, a educação, as politicas públicas, entre outros temas relevantes. Neste estudo, o foco está em levantar a representação social da pessoa idosa por jovens e adultos residentes no estado de Goiás.

De acordo com Moscovici (1981), a representação é um processo de nomeação e classificação que estabelece relações entre categorias e rótulos. O rótulo é formado pela afiliação e posição em uma matriz cultural de identidades. A representação remete à ideia de imagem, de modelo social, ao conteúdo concreto e limitado de um aspecto preciso do objeto de representação. Assim, entende-se por representação social o conjunto de conceitos, explicações e afirmações que se originam na vida diária, no curso de comunicações interindividuais.

Abric (1994a) postula que a representação funciona como sistema sociocognitivo e como sistema contextualizado. Quando um sujeito ativo produz representações acerca de um determinado objeto, trata-se do sistema sociocognitivo. No entanto, estas representações são determinadas inicialmente pelas condições sociais nas quais se elabora e se transmite uma representação, embora estejam submetidas às regras dos processos cognitivos. Trata-se, portanto, do sistema contextualizado que remete à questão dos significados, elemento fundamental da representação, pois este sistema é determinado pelo contexto discursivo ou social.

A partir do crescimento populacional da pessoa idosa, surge a necessidade de entender os conceitos que são estruturados pela representação social pautada em estereótipos que proporcionam o desenvolvimento de preconceitos que podem ser tanto positivos, quanto negativos. Infelizmente, muitos são os estereótipos negativos que levam a sociedade a formular representações sociais equivocadas sobre a pessoa idosa. 
De acordo com Moscovici (1981), a representação social pode ser vista sob três dimensões: a) informação, b) atitude ou valoração, c) campo de representação ou imagem. A informação é a organização dos conhecimentos que um grupo possui a respeito de um objeto social e pode ser completa ou incompleta, coerente ou incoerente. A atitude favorável, desfavorável, neutra é formada pela orientação global em relação ao objeto. E assim, segundo Abric (1994a), toda representação social recorta e simboliza atos e situações que acabam se tornando comuns e por isso as pessoas não devem ser passivas a esta situação, mas sim, devem ser ativas, buscando a reconstrução do objeto em um contexto de valores, reações e regras. O significado de uma representação deve ser observado a princípio pela natureza das condições do discurso, do contexto ideológico e do lugar que o individuo ou o grupo ocupa no sistema social que foi produzida tal representação.

Abric (1994b) afirma que "a representação é, pois, constituída por um conjunto de informações, de crenças, de opiniões e de atitudes sobre um objeto dado" (p. 16-17), ou seja, a cultura permeia a formação das representações. Assim, uma representação social é estabelecida sobre os traços típicos de um grupo, categoria ou classe social e atualmente os estereótipos estudados são os étnicos, de gênero, de profissão, de classe social e de ciclo de vida (AYESTERAN; PAES, 1987). Neste estudo, o foco está no estereótipo do ciclo de vida que possibilita levantar a representação social da pessoa idosa.

Abric (1994a) destaca que uma das principais preocupações com relação a representação social é o comportamento que surge a partir da representação estabelecida. Isso porque a representação funciona como uma antecipação das ações, quando intervém na finalidade da situação, no tipo de atitude cognitiva a ser adotada pelos sujeitos sociais, revelando, assim, sua natureza prescritiva. A função justificadora da representação atua a posteriori no sentido 
de justificar os comportamentos e tomadas de posição dos grupos e indivíduos numa ação ou com relação aos seus parceiros. Assim, entende-se que os comportamentos dos sujeitos não são determinados pelas características objetivas da situação, mas sim pela representação anterior a essa situação. As pesquisas a partir desta perspectiva abrem possibilidades de verificar como as pessoas pensam e agem em uma sociedade; se de forma preconceituosa ou não.

A cultura social é importante na formação das representações sociais. Conforme Rodrigues (2015), a cultura japonesa se diferencia da brasileira em relação à pessoa idosa. A velhice no Japão é sinônimo de sabedoria e de respeito, enquanto no Brasil é sinônimo de "caduquice", senilidade, desrespeito. Outra diferença cultural está na confiança estabelecida na pessoa idosa, quando os japoneses consultam seus anciãos antes de qualquer grande decisão, por considerarem seus conselhos sábios e experientes. Os brasileiros veem seus idosos como pessoas incapazes, após idade avançada, perdem o poder e a capacidade de tomar decisões sobre suas próprias vidas. Além disso, os japoneses idosos possuem atuação intensa nas decisões importantes de seus grupos sociais, especialmente nos destinos politicos, enquanto os brasileiros idosos ficam desobrigados de participar de eleições, como se fossem incapazes e inúteis à nação. Por fim, os idosos japoneses são tidos como referencial de ética, moralidade, honra e dignidade para os jovens, enquanto no Brasil, isso não é percebido.

Vale ressaltar que o estereótipo sofre influência direta do contexto cultural em que está inserido, e na atual sociedade reforça-se a visão da velhice como uma doença incurável, como um declínio inevitável, e a pessoa que envelhece está fadada ao fracasso. Formas de preconceito voltadas à pessoa idosa se caracterizam como uma representação social da gerontofobia, que é definida como o processo de estereotipia e de discriminação sistemática contra as pessoas, porque são velhas (STAAB; HODGES, 
1998). Nesse processo se associam conceitos e traços negativos integrados à incapacidade, à fraqueza, à inutilidade e a percepções pejorativas referentes aos fenômenos 'envelhecer' e 'velhice'.

De acordo com um estudo realizado por Champagne e Frennetna, na Université de Montreal, são quatorze os tipos de estereótipos mais frequentes em idosos:

Os idosos não são sociáveis e não gostam de se reunir; divertem-se e gostam de rir; temem o futuro; gostam de jogar às cartas e outros jogos; gostam de conversar e contar as suas recordações; gostam do apoio dos filhos; são pessoas doentes que tomam muita medicação; fazem raciocínios senis; não se preocupam com a sua aparência; são muito religiosos e praticantes; são muito sensiveis e inseguros; não se interessam pela sexualidade; são frágeis para fazer exercício físico; são na grande maioria pobres (CHAMPAGNE; FRENNETNA apud MARTINS; RODRIGUES, 2004, p. 251).

Essa análise da pesquisa chama a atenção para a confusão de conceitos existentes que se fazem, destacando como características da velhice traços de personalidade e fatores socioeconômicos ao invés de características específicas do envelhecimento. Mas a partir destes achados é possivel refletir sobre a existência de mitos relacionados ao envelhecimento que impedem os jovens e os adultos de manterem uma relação saudável com os idosos. Reforça-se também a necessidade de atentar para os mitos e estereótipos criados sobre a velhice, pois eles estão muitas vezes ligados ao desconhecimento do processo de envelhecimento, gerando sofrimento para os idosos e influenciando de forma negativa a interação das crianças, jovens e adultos com a pessoa idosa.

Trata-se de um estudo quanti-qualitativo, observacional, não analítico e de corte transversal, pois busca medir prevalências das representações sociais positivas e negativas em relação à pessoa idosa. 
Participaram deste estudo 146 pessoas, dessas 84,1\% são do sexo feminino e $15,9 \%$ masculino, com idade variada de 10 a 56 anos, em que $54,1 \%$ estão entre 15 a 22 anos. $82,1 \%$ são solteiros, $80,1 \%$ possuem ensino superior incompleto e $84,1 \%$ moram em Goiânia.

Para este estudo foi construído e validado um instrumento contendo uma escala que avalia representações sociais positivas e negativas sobre a pessoa idosa, assim como quatro itens para ver a representatividade do que é ser ve1ho. Esta escala varia de 1 (discordo), 2 (às vezes discordo e às vezes concordo) e 3 (concordo). Avaliou-se a consistência interna entre os itens e obteve-se para as representações sociais positivas $=0,70$, para as negativas $=0,82$ e para a representatividade do que é ser velho $=0,70$. Neste instrumento foram também inseridos itens para levantar sexo, idade, escolaridade, onde mora e estado civil.

Foi construído e validado o instrumento para avaliar a representação social da pessoa idosa a partir da teoria proposta por Pasquali (2003) "Teste referente a construto: teoria e modelo de construção". Assim, seguiram-se as etapas de procedimentos teóricos, experimentais e analíticos desta teoria.

Para coleta de dados, quando os participantes demonstraram clareza sobre a proposta da investigação, foi entregue o Termo de Consentimento Livre e Esclarecido (TCLE, conforme Resolução n. 466/2013 do Conselho Nacional de Saúde) às pessoas que quisessem participar deste estudo, e logo que o TCLE foi assinado, o instrumento foi aplicado a cada participante individualmente.

Os dados foram inseridos no programa estatístico SPSS-18 (Statistical Package for Social Sciences) e tratados por meio de análises: fatorial, de consistência interna entre os itens (alfa de Cronbach) e descritivas (frequência, porcentagem, média e desvio padrão). 


\section{Resultados e discussão}

Para avaliar as representações sociais sobre a pessoa idosa, primeiramente realizou-se a análise das representações negativas, em seguida das representações positivas e, por fim, das respostas à pergunta "Para você, o que é ser velho?".

Ao analisar o que surge de representações sociais negativas sobre a pessoa idosa, observa-se que ainda existem pessoas $(34,4 \%)$ que expressam que a pessoa idosa é sem vergonha, que fica ridicula com roupas sensuais $(50 \%)$, que não consegue gerir seus bens (24\%), que dá despesa $(46,4 \%)$, que virou mania querer priorizar as leis para os idosos $(17,2 \%)$, que eles deveriam ser colocados em abrigo (10,9\%), que demanda muito tempo para cuidar deles $(70,3 \%)$, que agentes $(85,4 \%)$ e comerciantes $(86,2 \%)$ aproveitam da ingenuidade deles, que haja paciência para as rabugices deles $(35,8 \%)$, que falta apoderamento de sua vida $(45,6 \%)$, que vai ficar com demência $(22,7 \%)$, que tem preguiça $(52,8 \%)$, que é cansativo $(46,6 \%)$, que é incompativel com o mundo de hoje $(28,9 \%)$, que serve para cuidar dos netos $(8,2 \%)$, que só devem namorar pessoas da mesma idade (30\%), que atrapalham a vida $(4,8 \%)$ e o mundo $(4,2 \%)$, que os programas sociais voltados para a pessoa idosa são suficientes $(17,8 \%)$, que é uma pessoa ultrapassada $(19,3 \%)$, que é doente $(13,2 \%)$, que é somente um baú de memórias $(13,8 \%)$, que devem ser mais contidos $(31,3 \%)$, que é um absurdo ter prioridades nas filas $(6,9 \%)$ e que é gastar dinheiro à toa, gastar dinheiro para construir hospitais para a pessoa idosa $(2,1 \%)$ (Tabela 1$)$.

O discurso sobre a sexualidade na velhice revela indiscretos preconceitos e a repetição de mitos populares acerca de idosos assexuados, sem vida amorosa, por abnegação sexual em favorecimento de uma experiência religiosa ou, ainda, idosos pervertidos, para quem o sexo só 
existe em caráter negocial (SILVA; PEDROSA, 2004). De acordo com Siqueira e Pereira (2007), diz-se que idoso não precisa de sexo, que é feio, que idoso não tem interesse sexual. Entretanto, quando se olha para o aspecto biológico e psicológico, estas pessoas apresentariam ampla capacidade de realização sexual e afetiva, pois a idade não retira a sexualidade do indivíduo.

O namoro na terceira idade pode contar ou não com a presença do sexo. Alterações físicas são capazes de modificar a forma como o sexo é realizado e vivenciado. Conforme Capodieci (2000), o namoro pode significar proteção, carinho, companhia. Ter um companheiro é muito importante e receber demonstrações de carinho não é errado, feio e nem sinônimo de fraqueza. Tempo de namoro é tempo de amar e, também, de ser amada (LAURENTINO, 2006) e nesse sentido, não importa a idade e sim a capacidade de nutrir e receber o sentimento do outro, sendo este da mesma idade ou não.

TABELA 1 - Representações negativas sobre a pessoa idosa

\begin{tabular}{|c|c|c|c|c|c|c|}
\hline Afirmativas & & Discordo & $\begin{array}{l}\text { Às vezes } \\
\text { discordo } \\
\text { ou } \\
\text { concordo }\end{array}$ & Concordo & $\mathbf{M}$ & Dp \\
\hline 3 - É sem vergonha & $\%$ & 65,5 & 23,4 & 11,0 & 1,5 & 0,7 \\
\hline $\begin{array}{l}4 \text { - Ficam ridículos com } \\
\text { roupas sensuais }\end{array}$ & $\%$ & 43,8 & 21,9 & 34,2 & 1,9 & 0,9 \\
\hline $\begin{array}{l}5 \text { - Falta capacidade de } \\
\text { gerir seus bens }\end{array}$ & $\%$ & 76,0 & 15,8 & 8,2 & 1,3 & 0,6 \\
\hline 6 - Dá despesa & $\%$ & 53,4 & 28,1 & 18,5 & 1,7 & 0,8 \\
\hline $\begin{array}{l}7 \text { - Virou mania querer } \\
\text { priorizar as leis para } \\
\text { os idosos }\end{array}$ & $\%$ & 82,8 & 10,3 & 6,9 & 1,2 & 0,6 \\
\hline $\begin{array}{l}8 \text { - Deveriam ser } \\
\text { colocados em } \\
\text { abrigos }\end{array}$ & $\%$ & 89,0 & 8,2 & 2,7 & 1,1 & 0,4 \\
\hline
\end{tabular}


(Continuação)

\begin{tabular}{|c|c|c|c|c|c|c|}
\hline Afirmativas & & Discordo & $\begin{array}{l}\text { Às vezes } \\
\text { discordo } \\
\text { ou } \\
\text { concordo }\end{array}$ & Concordo & $\mathbf{M}$ & Dp \\
\hline $\begin{array}{l}12 \text { - Demanda muito } \\
\text { tempo para cuidar }\end{array}$ & $\%$ & 29,7 & 43,4 & 26,9 & 2,0 & 0,8 \\
\hline $\begin{array}{l}13 \text { - Agentes de viagem } \\
\text { aproveitam da } \\
\text { ingenuidade delas }\end{array}$ & $\%$ & 14,6 & 41,0 & 44,4 & 2,3 & 0,7 \\
\hline $\begin{array}{l}14 \text { - Haja paciência } \\
\text { para as rabugices }\end{array}$ & $\%$ & 63,2 & 24,3 & 12,5 & 1,5 & 0,7 \\
\hline $\begin{array}{l}15 \text { - Comerciantes } \\
\text { aproveitam da } \\
\text { ingenuidade delas }\end{array}$ & $\%$ & 13,8 & 40,0 & 46,2 & 2,3 & 0,7 \\
\hline $\begin{array}{l}16 \text { - Falta apoderamento } \\
\text { de sua vida }\end{array}$ & $\%$ & 54,5 & 35,9 & 9,7 & 1,6 & 0,7 \\
\hline $\begin{array}{l}17 \text { - Vai ficar com } \\
\text { demência }\end{array}$ & $\%$ & 77,2 & 11,0 & 11,7 & 1,3 & 0,7 \\
\hline 21 - Tem preguiça & $\%$ & 47,3 & 38,4 & 14,4 & 1,7 & 0,7 \\
\hline 22 - É cansativo & $\%$ & 53,4 & 32,9 & 13,7 & 1,6 & 0,7 \\
\hline $\begin{array}{l}23 \text { - É incompatível com } \\
\text { o mundo de hoje }\end{array}$ & $\%$ & 71,0 & 17,2 & 11,7 & 1,4 & 0,7 \\
\hline $\begin{array}{l}25 \text { - Só serve para } \\
\text { cuidar dos netos }\end{array}$ & $\%$ & 91,7 & 3,4 & 4,8 & 1,1 & 0,5 \\
\hline $\begin{array}{l}26 \text { - Só deve namorar } \\
\text { pessoas com a } \\
\text { mesma idade }\end{array}$ & $\%$ & 69,0 & 17,9 & 13,1 & 1,4 & 0,7 \\
\hline $\begin{array}{l}28 \text { - Atrapalham a } \\
\text { nossa vida }\end{array}$ & $\%$ & 95,2 & 3,4 & 1,4 & 1,1 & 0,3 \\
\hline $\begin{array}{l}29 \text { - Os programas } \\
\text { sociais voltados } \\
\text { para os idosos são } \\
\text { suficientes }\end{array}$ & $\%$ & 82,2 & 9,6 & 8,2 & 1,3 & 0,6 \\
\hline $\begin{array}{c}32 \text { - É uma pessoa } \\
\text { ultrapassada }\end{array}$ & $\%$ & 80,7 & 15,9 & 3,4 & 1,2 & 0,5 \\
\hline $\begin{array}{l}34 \text { - Atrapalha o } \\
\text { mundo }\end{array}$ & $\%$ & 95,9 & 2,1 & 2,1 & 1,1 & 0,3 \\
\hline
\end{tabular}


(Conclusão)

\begin{tabular}{|c|c|c|c|c|c|c|}
\hline Afirmativas & & Discordo & $\begin{array}{l}\text { Às vezes } \\
\text { discordo } \\
\text { ou } \\
\text { concordo }\end{array}$ & Concordo & $\mathbf{M}$ & Dp \\
\hline 35 - Só doente & $\%$ & 86,8 & 6,9 & 6,3 & 1,2 & 0,5 \\
\hline $\begin{array}{l}37 \text { - É somente um baú } \\
\text { de memórias }\end{array}$ & $\%$ & 86,2 & 9,0 & 4,8 & 1,2 & 0,5 \\
\hline $\begin{array}{l}40 \text { - Devem ser mais } \\
\text { contidos }\end{array}$ & $\%$ & 69,0 & 21,4 & 9,7 & 1,4 & 0,7 \\
\hline $\begin{array}{l}41 \text { - É um absurdo ter } \\
\text { prioridades nas } \\
\text { filas... }\end{array}$ & $\%$ & 93,1 & 2,1 & 4,8 & 1,1 & 0,4 \\
\hline $\begin{array}{l}42 \text { - É gastar dinheiro } \\
\text { à toa construir } \\
\text { hospital específico } \\
\text { para as pessoas } \\
\text { idosas }\end{array}$ & $\%$ & 97,9 & 0,7 & 1,4 & 1,0 & 0,2 \\
\hline
\end{tabular}

Fonte: Elaboração das autoras.

Para Andrade (2003), velhice e doença são conceitos que caminham juntos no discurso das pessoas; no entanto, é possível notar que não foi isso o que os resultados deste estudo revelaram, sendo que apenas 13,2 das respostas concordam que idoso é doente. Conforme o autor (p. 211) saúde denota disposição, estado de ânimo, motivação, enquanto doença tem a ver com estado de indisposição, falta de motivação para a vida. Desse modo, fica evidenciado que embora haja a presença de alguma doença física, a pessoa idosa não se considera doente, pois suas habilidades de enfrentamento são maiores que o diagnóstico de alguma patologia.

Os idosos, de acordo com os resultados, são pessoas que demandam muito tempo de cuidado. Esta é uma concepção que está estreitamente ligada ao binômio velhice-doença. Del Duca, Thume e Hallal (2011) defendem que para que este paradigma seja quebrado tanto na concepção dos 
indivíduos, tanto para diminuir os cuidados que são dispensados aos idosos, em especial aos dependentes, é preciso que se invista em politicas de saúde destinadas aos idosos que trabalhem com a potencialização da capacidade funcional, intervenções que levem autonomia a esses sujeitos, técnicas de autocuidado seguras e participação social.

Os cuidados com os idosos vão além do próprio indivíduo e de sua família. Os cuidados inerentes aos idosos também podem ser de caráter preventivo, desta forma, profissionais capacitados para promover maiores habilidades, maior autonomia, segurança na realização de suas atividades diárias; profissionais estes ligados à gerontologia, que é a ciência que estuda o processo de envelhecimento em suas mais diversas dimensões e abarca profissionais médicos, enfermeiros, fisioterapeutas, psicólogos, educadores físicos, entre outros profissionais da saúde.

Das respostas coletadas, $46,4 \%$ concordam que pessoas acima de 60 anos só dão despesas. Entretanto, Ocké Reis (2000), analisando os dados coletados na Pesquisa de Orçamentos Familiares, realizada pelo IBGE, 1995/96, demonstrou que a despesa dos idosos concentra-se 40\% em gastos com remédios e planos de saúde, seguido de $28 \%$ de gastos com profissionais de saúde, $6 \%$ com gastos de óculos, $4 \%$ de prestadores hospitalares e serviços terapêuticos, cada um.

Magnabosco-Martins, Vizeu-Camargo e Biasus (2009) realizaram um estudo sobre as representações sociais dos idosos para diferentes faixas etárias e obtiveram como resultados definições de que o idoso é alguém que merece cuidado, precisa de carinho, atenção, respeito, paciência, já viveu muito e tem muita experiência para passar às pessoas. O que está de acordo com os resultados alcançados com os questionários deste estudo, pois $96,6 \%$ disseram que os idosos têm muito a ensinar, 93,6\% que eles conhecem muito, e $97,2 \%$ que precisam de envolvimentos afetivos, ressaltando que este envolvimento pode ser com familiares, amigos e companheiros. 
Quanto a autonomia dos idosos, os itens "pode viajar sozinho" $84,8 \%$ e "tem capacidade de cuidar da sua casa sozinha" $83,5 \%$ concordam. Para Vieira (2004), a autonomia na velhice é comumente faz com que seja construída uma representação de que a pessoa idosa não pode desempenhar suas tarefas na sociedade, sendo esta uma questão fundamental para a manutenção da qualidade de vida. $\mathrm{O}$ item "falta capacidade para gerir seus bens," aponta que $45,6 \%$ dos participantes concordam com esta negativa.

TABELA 2 - Representações positivas sobre a pessoa idosa

\begin{tabular}{|c|c|c|c|c|c|c|}
\hline Representações Positivas & & Discordo & $\begin{array}{l}\text { Às vezes } \\
\text { discordo ou } \\
\text { concordo }\end{array}$ & Concordo & M & Dp \\
\hline 2 - Tem vida ativa & $\%$ & 7,6 & 27,6 & 64,8 & 2,6 & 0,6 \\
\hline $\begin{array}{l}10 \text { - Tem muito a contribuir } \\
\text { com a sociedade }\end{array}$ & $\%$ & 2,7 & 12,3 & 84,9 & 2,8 & 0,5 \\
\hline 11 - Sabe ensinar & $\%$ & 3,4 & 14,4 & 82,2 & 2,8 & 0,5 \\
\hline $\begin{array}{l}18 \text { - Tem capacidade de } \\
\text { cuidar de sua casa } \\
\text { sozinha }\end{array}$ & $\%$ & 16,6 & 36,6 & 46,9 & 2,3 & 0,7 \\
\hline 19 - É divertida & $\%$ & 4,1 & 30,1 & 65,8 & 2,6 & 0,6 \\
\hline 20 - Conhece muito & $\%$ & 3,4 & 13,0 & 83,6 & 2,8 & 0,5 \\
\hline Representações Positivas & & Discordo & $\begin{array}{l}\text { Às vezes } \\
\text { discordo ou } \\
\text { concordo }\end{array}$ & Concordo & $\mathbf{M}$ & Dp \\
\hline $\begin{array}{l}24 \text { - Aprende as coisas novas } \\
\text { que são ensinadas }\end{array}$ & $\%$ & 16,6 & 36,6 & 46,9 & 2,3 & 0,7 \\
\hline $\begin{array}{l}27 \text { - Precisam frequentar } \\
\text { reuniões sociais }\end{array}$ & $\%$ & 17,9 & 22,1 & 60,0 & 2,4 & 0,8 \\
\hline 33 - Pode viajar sozinha & $\%$ & 15,2 & 34,5 & 50,3 & 2,4 & 0,7 \\
\hline 36 - É interessante & $\%$ & 2,1 & 18,6 & 79,3 & 2,8 & 0,5 \\
\hline $\begin{array}{l}38 \text { - É capaz de manter bons } \\
\text { relacionamentos com os } \\
\text { jovens }\end{array}$ & $\%$ & 3,4 & 11,7 & 84,8 & 2,8 & 0,5 \\
\hline $\begin{array}{l}39 \text { - Precisa de } \\
\text { envolvimentos afetivos }\end{array}$ & $\%$ & 2,8 & 9,8 & 87,4 & 2,8 & 0,4 \\
\hline
\end{tabular}

Fonte: Elaboração das autoras. 
Em relação às representações sociais positivas, observa-se que as pessoas que responderam à escala afirmam que a pessoa idosa tem vida ativa $(92,4 \%)$, tem muito a contribuir com a sociedade $(87,2 \%)$, sabe ensinar $(96,6 \%)$, tem capacidade de cuidar de sua casa sozinha $(83,5 \%)$, é divertida (95,9\%), conhece muito $(93,6 \%)$, aprende as coisas novas que são ensinadas $(83,5 \%)$, precisam frequentar reuniões sociais $(82,1 \%)$, pode viajar sozinho $(84,8 \%)$, é interessante $(97,9 \%)$, é capaz de manter bons relacionamentos com os jovens $(96,5 \%)$ e precisa de envolvimentos afetivos $(97,2 \%)$ (Tabela 2$)$.

Quando perguntado às pessoas que participaram deste estudo, o que é ser velho, foi indicado como sinônimo: 'é uma pessoa idosa', 'é vovozinha(o)', 'é uma pessoa velha' 'e está na terceira idade', ao responderem em uma escala de concordância, observou-se que 91,8\% conceituam o velho como 'pessoa idosa' e 89,1\% como 'está na terceira idade', 63\% como 'vovozinha(o)' e como 'uma pessoa velha' $(53,4 \%)$ (Tabela 3). Neri e Freire (2000) afirmam que a substituição dos termos velho, velhice, idosos, terceira idade, melhor idade é indicativo de preconceito, sendo uma forma de mascarar novas representações sociais de pessoas acima de 60 anos. Peixoto (1998) contribui ao dizer que ao invés de ocorrerem mudanças nas politicas públicas e sociais, o que aconteceu foram inúmeras formulações teóricas, e não éticas, em torno da velhice.

TABELA 3 - Representações sobre 'o que é ser velho'

\begin{tabular}{lccccc}
\hline Afirmativas & Discordo & $\begin{array}{c}\text { Às vezes discordo } \\
\text { ou concordo }\end{array}$ & Concordo & M & Dp \\
\hline 1 - É uma pessoa idosa & 8,3 & 9,7 & 82,1 & 2,7 & 0,6 \\
$\begin{array}{l}\text { 9 - É vovozinha } \\
\text { (vovozinho) }\end{array}$ & 37,0 & 30,1 & 32,9 & 2,0 & 0,8 \\
30 - É uma pessoa velha & 46,6 & 17,8 & 35,6 & 1,9 & 0,9 \\
$\begin{array}{l}31 \text { - É estar na terceira } \\
\text { idade }\end{array}$ & 11,0 & 5,5 & 83,6 & 2,7 & 0,6 \\
\hline
\end{tabular}

Fonte: Elaboração das autoras. 
Para Debert (1988), os termos terceira idade e idoso parecem ter sido criados como sinônimos de envelhecimento ativo, independente, autônomo, com cunho de respeito para com as pessoas acima de 60 anos, no entanto, afirma que a construção desta definição não passa de um produto elaborado pelos sistemas de aposentadorias juntamente com as instituições e agentes responsáveis pelo tratamento da velhice que lutavam por maiores condições de qualidade de vida. Todo esse processo na busca de extinguir o uso do termo velho, sinônimo de decadência.

\section{Considerações finais}

O velho e o novo são termos paradoxais presentes em nossa sociedade. A contemporaneidade, onde há a valorização do novo e a negação do velho, favorece para que os mitos e os estereótipos sobre a pessoa idosa surjam nas interações e nas comunicações no interior dos grupos sociais. Pesquisar e estudar sobre a representação social da pessoa idosa na percepção dos jovens e adultos do estado de Goiás possibilitou conhecer sobre as representações negativas e positivas que essas percepções apresentam.

Abric (1994b) aponta que a cultura interfere na formação das representações sociais formadas em uma sociedade e os dados desta pesquisa corroboram com as afirmações apresentadas por Rodrigues (2015) que pontua sobre a diferença entre a cultura japonesa e a brasileira em relação à pessoa idosa. Diferente do Japão, no Brasil, velhice é sinônimo de "caduquice", senilidade, desrespeito, os brasileiros veem seus idosos como pessoas incapazes, que perdem o poder e a capacidade de tomar decisões sobre suas próprias vidas, incapazes e inúteis à nação. Ou seja, os idosos no Brasil estão longe de serem considerados como referencial de ética, moralidade, honra e dignidade, haja vista as politicas atuais, principalmente as políticas de saúde e de aposentadoria que 
circulam no Congresso Nacional e que desconsideram conquistas referentes ao direito da pessoa idosa.

Pode-se dizer que a partir dos resultados aqui apresentados há uma busca pela mudança da representação da pessoa idosa que, segundo as teorias apresentadas por Abric (1994a; b) e Moscovici (1981), está mais em processo sociocognitivo ou de informações do que propriamente dito no sistema de contextualização ou atitudes valorativas ou de representação. Visto que quando se pergunta 'o que é ser velho', há mudança no discurso da palavra vovozinha e pessoa velha para o discurso sociocognitivo ou de informações para pessoa idosa ou terceira idade. Nomenclaturas que não geram mudanças significativas na forma de tratamento voltado para a pessoa idosa, estão muito mais a nivel ideal do que seja pessoa idosa do que no real.

Quando confrontados os resultados positivos com os negativos, foi possivel observar que as representações negativas são mais evidentes e acabam contradizendo as positivas em alguns aspectos. Ao mesmo tempo em que consideram as pessoas idosas como divertidas, já as acham ridiculas com roupas sensuais; consideram os idosos ativos, também sobressai a percepção de que demandam muito tempo para cuidar deles e que são ingênuos e as pessoas aproveitam deles. Esses conceitos distorcidos e pouco explicativos sobre a pessoa idosa reforçam o preconceito e os mitos no imaginário das pessoas, apontando reflexos dos contextos culturais, sociais e políticos em que os jovens e adultos estão.

Vivemos em um momento social em que a solidariedade, o respeito, a compaixão e o amor ao próximo, independente da idade que apresenta, devem ser questionados e repensados. Estudos futuros, com ampliação da amostra, se fazem necessários, assim como continuar fomentando discussões, com o objetivo de emergirem novos conceitos positivos e inclusivos, redefinindo o papel do idoso, dando novos significados atribuídos e construídos a partir da 
vivência de cada um e valorizar a velhice enquanto um ciclo de vida natural. Enfim, as pesquisas devem contribuir para as reflexões de mudanças sobre o que é ser velho e de como os jovens devem perceber as pessoas idosas. 


\section{Referências}

ABRIC, Jean-Claude. Pratiques socials et représentations. Paris: Presses Universitaires de France, 1994a.

ABRIC, Jean-Claude. L'étude experimental e desreprésentations sociales. In: JODELET, D. (Ed.). Les représentations sociales. Paris: Presses Universitaires de France, 1994b.

ANDRADE, Oseias Guimarães de. Representações sociais de saúde e de doença na velhice. Acta sci., Health sci, v. 25, n. 2, p. 207-213, 2003.

AYESTERAN S. de Rosa, A. S.; PAES, D. Representación social, procesos cognitivos y desarrollo de la cognición social. In: PAES, D. (Ed.) Pensamiento, Individuo y sociedad. Cognición y representación social. Madrid: Editorial Fundamentos, p. 16-66, 1987.

CAPODIECI, Salvatore. A idade dos sentimentos: amor e sexualidade após os sessenta anos. Bauru: Edusc, 2000.

DEBERT, Guita Grin. A antropologia e o estudo dos grupos e das categorias de idade. Velhice ou terceira idade, v. 3, p. 49-67, 1998.

DEL DUCA, Giovâni Firpo; THUME, Elaine; HALLAL, Pedro Curi. Prevalência e fatores associados ao cuidado domiciliar a idosos. Rev. Saúde Pública, São Paulo, v. 45, n. 1, p. 113120, fev. 2011.

INSTITUTO BRASILEIRO DE GEOGRAFIA E ESTATISTICA. Censo demográfico 2010. Disponível em: http:/ /www.ibge. gov.br/home/estatistica/populacao/censo2010/. Acesso em abril 2012.

LAURENTINO, Norma R. Salini et al. Namoro na terceira idade e o processo de ser saudável na velhice: recorte ilustrativo de um grupo de mulheres. Revista Brasileira de Ciências do Envelhecimento Humano, v. 3, n. 1, 2006. 
MAGNABOSCO-MARTINS, Claudia Regina; VIZEU-CAMARGO, Brígido; BIASUS, Felipe. Representações sociais do idoso e da velhice de diferentes faixas etárias. Universitas Psychologica, v. 8, n. 3, p. 831-847, 2009.

MARTINS, Rosa Maria Lopes; RODRIGUES, Maria de Lurdes Martins. Estereótipos sobre idosos: uma representação social gerontofóbica. Millenium. Revista do ISPV, 29, p. 249-254, 2004.

MOSCOVICI, Serge. The phenomenonof social representations. In: FARR, R. M; MOSCOVICI, S (Orgs). Social representations. Cambridge University Press, p. 3-69,1981.

NERI, Anita Libetalesso; FREIRE, Sueli Aparecida. (Orgs.). E por falar em boa velhice. Campinas: Papirus, 2000.

OCKÉ REIS, Carlos Otávio. O gasto dos idosos em saúde: sinal dos tempos. Como vai: população brasileira, v. 5, n. 1, p. 41-50, mar. 2000.

PASQUALI, Luiz. Teste referente a constructo: teoria e modelo de construção em Instrumento psicológico: manual prático de elaboração. Brasília: LabPAM, IBAPP, 2003.

PEIXOTO, Clarice. Entre o estigma e a compaixão e os termos classificatórios: velho, velhote, idoso, terceira idade. Velhice ou terceira idade, v. 2, 1998.

RODRIGUES, Marcos Antônio Vasco. PARALELO: como são tratados os idosos no Japão e no Brasil. Reeditado em 20/04/2015. Disponivel em: <http://www.recantodasletras.com.br/artigos/5178916>. Acesso em: $11 \mathrm{dez} .2006$.

SILVA, Anna Cruz de Araújo Pereira da; PEDROSA, Aline da Silva. Sexualidade e etarismo: análise do discurso em uma lista de debates na internet. Estudos Interdisciplinares sobre o Envelhecimento, v. 13, n. 2, 2004. 
SIQUEIRA, Teresa Cristina Barbo; PEREIRA, Alciane Barbosa Macedo. Terceira Idade e Sexualidade: um encontro possivel? Fragmentos de Cultura, v. 17, n. 2, p. 271-277, 2007.

SOUSA, Ivone Félix de; CASTRO, Marli Bueno de; SÁ, Eline Alcoforado Maranhão de. A realidade social do idoso e a politica de assistência social. Fragmentos de Cultura, Goiânia, v. 22, n. 1, p. 81-96, jan./mar. 2012.

STAAB, Angela Simon; HODGES, Linda Compton. Enfermería gerontológica: adaptaciónal proceso de envejecimiento. México: MacGraw-Hill Interamericana, 1998.

TERRA, Newton Luiz; SILVA, Roberta; SCHIMIDT, Olavo Forlin. Tópicos em geriatria II. 2009. Disponivel em: http:// www.pucrs.br/revista/pdf/0138.pdf Acesso em: 20 maio. 2012.

VIEIRA, Eliane Brandão. Manual de Gerontologia: um guia teórico-prático para profissionais, cuidadores e familiares. Rio de Janeiro: Revinter, 2004. 